\title{
PATCHOULI ALKOHOL ISOMERS POGOSTEMON HERBA PREDICTED VIRTUALLY
}

\author{
Sentot Joko Raharjo $\left.{ }^{*}\right)\left({ }^{* *}\right)$, Chanif Mahdi ${ }^{* * *}$, Nurdiana ${ }^{* * * *}$, Wolfgang Nellen ${ }^{\star * * *}$ and Fatchiyah Fatchiyah ${ }^{\star * * * *}$ \\ ${ }^{\star}$ Student of Department of Biology, Faculty of Science, Brawijaya University, Indonesia \\ ${ }^{* *}$ Academic of Pharmacy and Food Analysis, Putra Indonesia Malang, Indonesia \\ ${ }^{* * *}$ Chemistry Department, Faculty of Science, Brawijaya University, Indonesia \\ ${ }^{* * *}$ Medicine Pharmacology, Faculty of Medicine, Brawijaya University, Indonesia \\ $* \star * \star \star$ Kassel University, Germany \\ $* * * * * *$ Biology Department, Faculty of Science, Brawijaya University, Indonesia, \\ Corresponding author Email: fatchiya@ub.ac.id and fatchiya@gmail.com ; Phone: +62341575841
}

\section{ABSTRACT}

The aim of our research is predicting the alpha-patchouli alcohol isomer Pogostemon Herba as inhibitors cyclooxygenase (COX-1 and COX-2) isoenzymes. The data for the alpha-patchouli alcohol isomer (CD521903, CD442384, and/or CD6432585) Pogostemon Herba were explored from the pubchem database. Molecular interaction studies with COX-1 and COX-2 from mouse were done using the molecular docking tools Hex 6.12 and LeadIT2 Bisolve. The analysis of the alpha-patchouli alcohol compounds of patchouli oil showed that alpha-Patchouli alcohol (CD521903) binds to COX-1 at active sites including: LEU223B, ASP228B, LEU237B, ARG 332B, TRP 138A, GLU 139A, SER 142A, ASN 143A, and the interaction to COX-2 at active site including: GLN 289B, GLU 290B, ARG 222B, LYS 211B, THR 212B, HIS 214B, ASN 382B, HEM682B, GLN 454B, HIS 386B, TRP 387B, HIS 388B, VAL 274B, GLN 203B, VAL 291B, VAL 295B. The interaction hydrogen bond energy between alpha-patchouli alcohol: (CD521903-COX-1 complexes $(-4 \mathrm{~kJ} / \mathrm{mol})$ and CD521903-COX-2 complexes $(-8 \mathrm{~kJ} / \mathrm{mol})$ by LeadIT2 Biosolve. This suggests alpha-patchouli alcohol CD521903 as candidate for a selective COX-2 inhibitor. These in silico data need further analyses of biological function activity.

Keywords: alpha-patchouli alcohol, COX-1/ COX-2, inhibitor selective, predicted virtually

\section{INTRODUCTION}

Secondary metabolites of patchouli plant were grouped into non-volatile compounds (Wang et al., 2010) and volatile compounds (patchouli oils). alpha patchouli alcohol was the major compounds of patchouli oil (Raharjo S.J. \& Retnowati R., 2012). alpha-patchouli alcohol has the effect of anti-inflammatory activity, by regulating the mRNA expression of the panel of inflammatory mediators, including TNF- $\alpha$, IL- $1 \beta$, iNOS and COX-2 (Xian et al., 2011). Molinspiration analysis of major compounds of patchouli oil predict activities as inhibitors for e,g, kinases, proteases and nuclear receptors (Raharjo S.J. \& Fatchiyah, 2013). The data for the alpha-patchouli alcohol isomer (CD521903, CD442384, and/or CD6432585) Pogostemon Herba were explored from the pubchem database.

Cyclooxygenase enzymes exist in two isoforms, cyclooxygenase-1 (COX-1) and cyclooxygenase-2 (COX-2) (Dannhardt \& Laufer, 2000). Both isoforms differ in tissue distribution and have different regulatory functions. COX-1 is a constitutive enzyme that catalyzes the regulatory prostanoid formation in various tissues, especially in mucous membranes of the gastrointestinal tract, in kidneys, platelets and vascular epithelium. In contrast, $\mathrm{COX}-2$ is induced, by inflammation, mutagenesis or ontogenesis. COX-2 leads to the production of prostanoid mediators for pain and inflammation (Dannhardt \& Laufer 2000). This led to the hypothesis that COX-1 catalyzes the formation of prostaglandins for carrying out physiological regulatory functions, whereas COX-2 catalyzes the formation of "bad" prostaglandins that cause inflammation (Kartasasmita, 2002). The hypothesis explains that classic NSAID (Non Sterol Anti Inflamantory Drugs) toxicity in the gastrointestinal tract caused by drugs like acetyl salicylic acid, phenylbutazone, indomethacin, diclofenak, ibuprofen and naproxen is due to the non-selectivity for COX-1 and COX-2 (Dannhardt \& Laufer, 2000).

A strategy to reduce the toxicity of classical NSAIDs could be selective inhibition of COX-2. Structurally, there are several classes of selective COX-2 inhibitors, namely: (1) derivatives carboxylic and heterocyclic to bound vicinal with moieties aril,
(2) derived diaryl- or aryl /heteroaryl- ethers and thioethers, (3) cis-stilbene derivative, and (4) diaryl ketones and aryl/ heteroaryl. Until the year 2000 about 500 compounds have been synthesized that are selective COX-2 inhibitors (Dannhardt $\&$ Laufer, 2000). Celecoxib ${ }^{\star}$ and Rofecoxib ${ }^{\star}$ are compounds, which have passed clinical trials and are on the market. In patients with osteo- and rheumatoid arthritis, selective COX-2 inhibitors exhibit anti-inflammatory function which is equivalent to the classical NSAIDs, but with milder toxicity in the gastrointestinal tract. However, an increase in blood pressure was also reported as a side effect of selective COX-2 inhibitors (Kartasasmita, 2002). Even though selective COX-2 inhibitors are milder drugs, care has to be taken to monitor and avoid potential side effects.

Virtual modeling can be used as a preliminary analysis prior to functional tests enzyme inhibitors. Therefore, we screened the alpha-patchouli alcohol isomer compounds from patchouli oil using their structures from the pubchem database docking tools with COX-1 and COX-2 to visualize molecular interactions. Virtual modeling can be used as a preliminary analysis prior to in vitro analysis of enzyme inhibitor COX conformation.

\section{MATERIAL AND METHOD}

\section{Patchouli Oil}

Alpha-patchouli alcohol isolated form patchouli oil. Patchouli oil obtained from the steam distillation of Pogostemon Herba (Pogostemon cablin Benth) for 8 hours (Raharjo S.J. \& Yusuf AY, 2012) and isolation of alpha-patchouli alcohol compounds of patchouli oil by using column chromatography (Tsai et al., 2007). The identification of major compounds was accomplished by using the Gas Chromatography-Mass Spectrometric (GC-MS) to major compounds analysis with GCMS Shimadzu QP-2010S, column Rtx-5MS, length 30 meters, and Wiley8 library (Raharjo S.J., Retnowati R., \& Soebiantoro, 2012).

\section{Retrieval of Target Sequence}

3D model was obtained from SWISS-MODEL reposi- 
tory for cyclooxgenase-1 (COX-1) ID: EDL_08676.1 (http:// swissmodel.expasy.org/repository) and 3D model from PDB ID : 6COX for cyclooxygenase-2 (COX-2) ID: EDL_39487 (Zukhrullah \& Aswad, 2012).

\section{Ligand Preparation}

Alpha-patchouli alcohol compounds was downloaded from pubchem.ncbi.nlm.nih.gov (http://pubchem.ncbi.nlm.gov) then its energy form were minimized and converted to PDBformat by Open Babel 2.3.1 (http://openbabel.org/) as ligand for virtual screening.

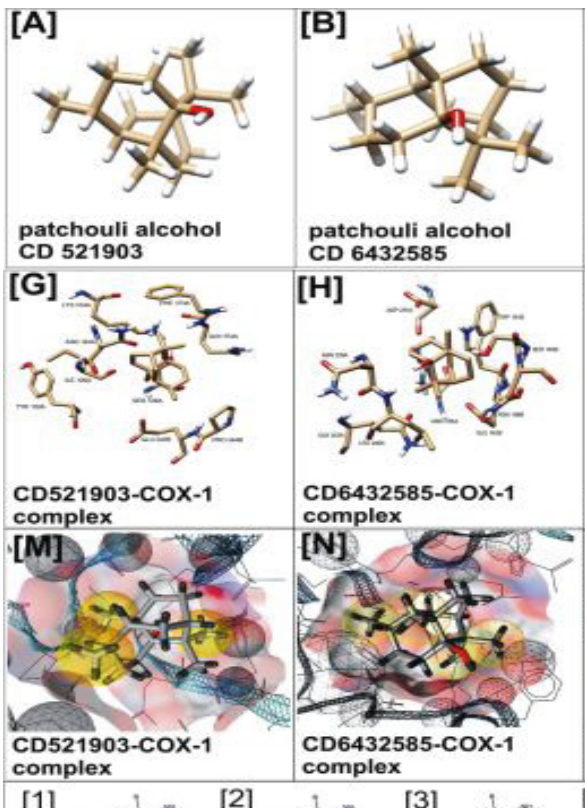

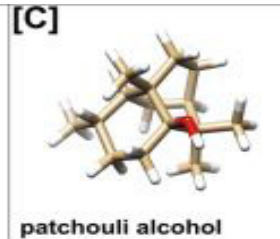

patchouli alcoho [I] D- 0

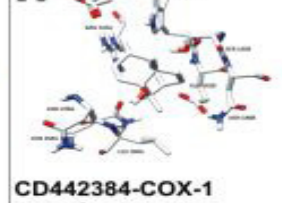
CD442384-COX-1 complex

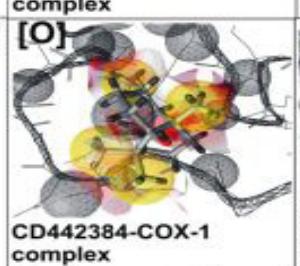

\section{Docking Ligand - Protein}

We used the rigid docking by Hex 6.12 software (http://hex. loria.fr) to compute possible interaction COX-1 and COX-2 with alpha-Patchouli alcohol isomer (CD521903, CD442384 and CD6432585) on its interaction site. Output of rigid docking were refined using InteLigand-LigandScout 2.02 software (http://ligandscout.software.informer.com) to perform Identification of Van Der Walls Interaction and LeadIT2 software. And also, we used LeadIT2 software to simulate most possible native complex structure of alpha-Patchouli alcohol isomer
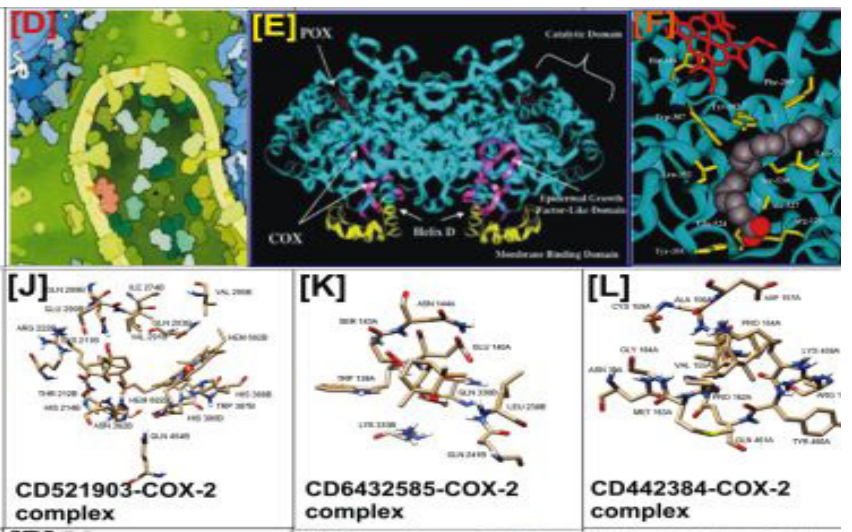

[4] of [5] th, ${ }^{[6]}$ the ${ }^{[7]}$,

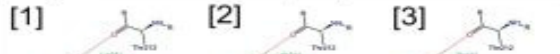
[P]<smiles>c1ccc(-c2cccc(C3CC4CCC3C4)c2)cc1</smiles>

[10]
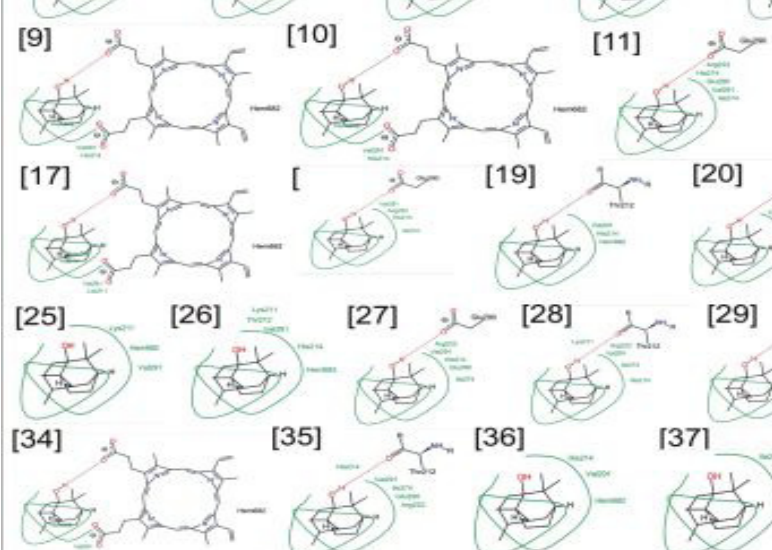

[35]

[27]

[19] [20]
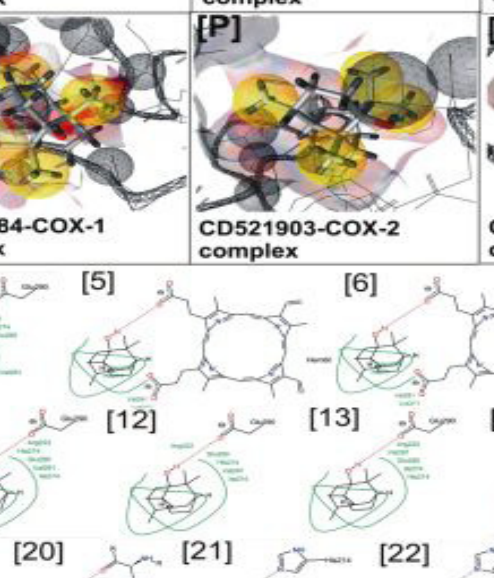

[R:

complex
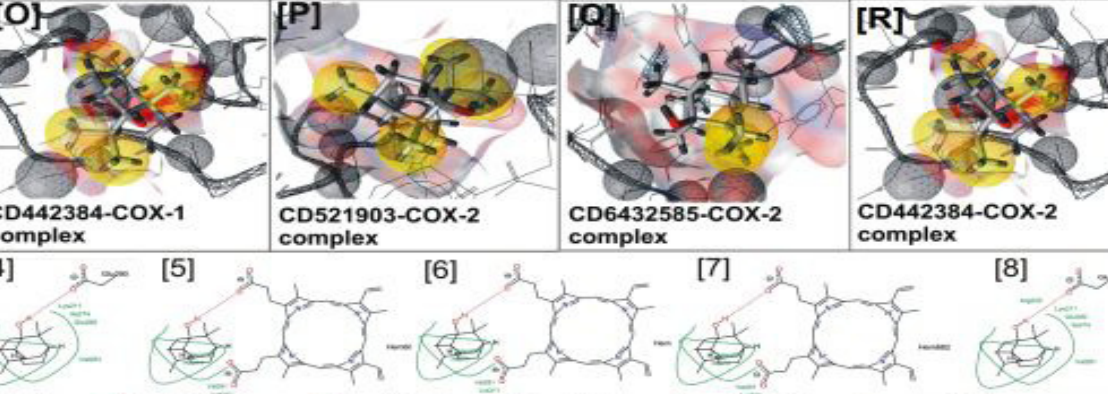

[8] 20
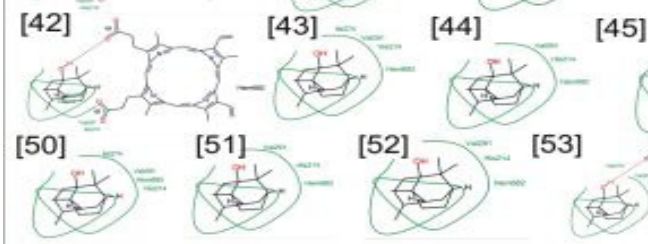

[59]

[60]
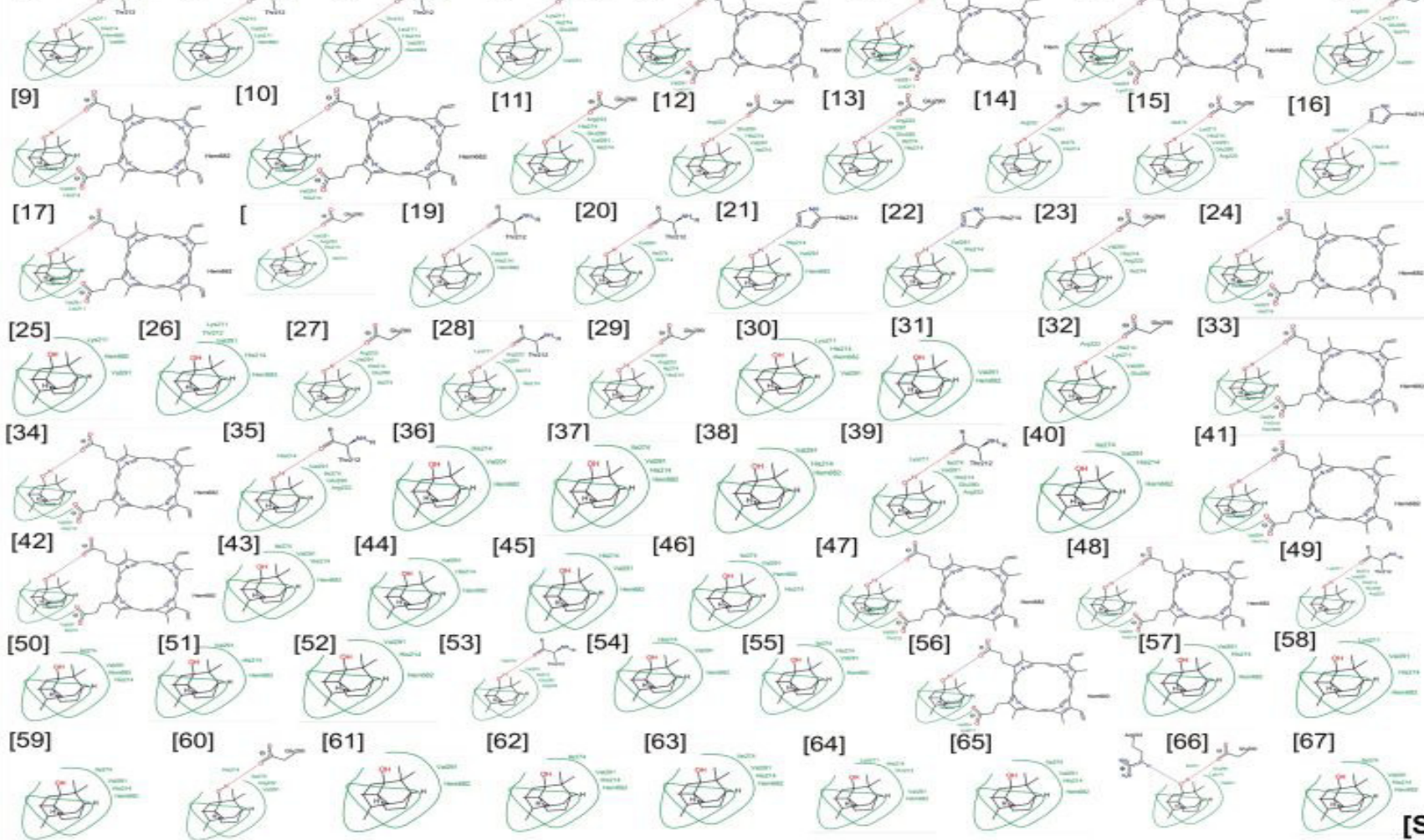

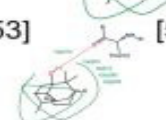

[62]

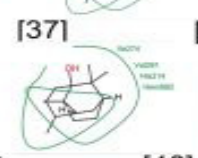

「371

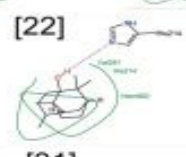

[31]
[14]

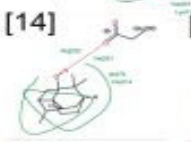

[23]
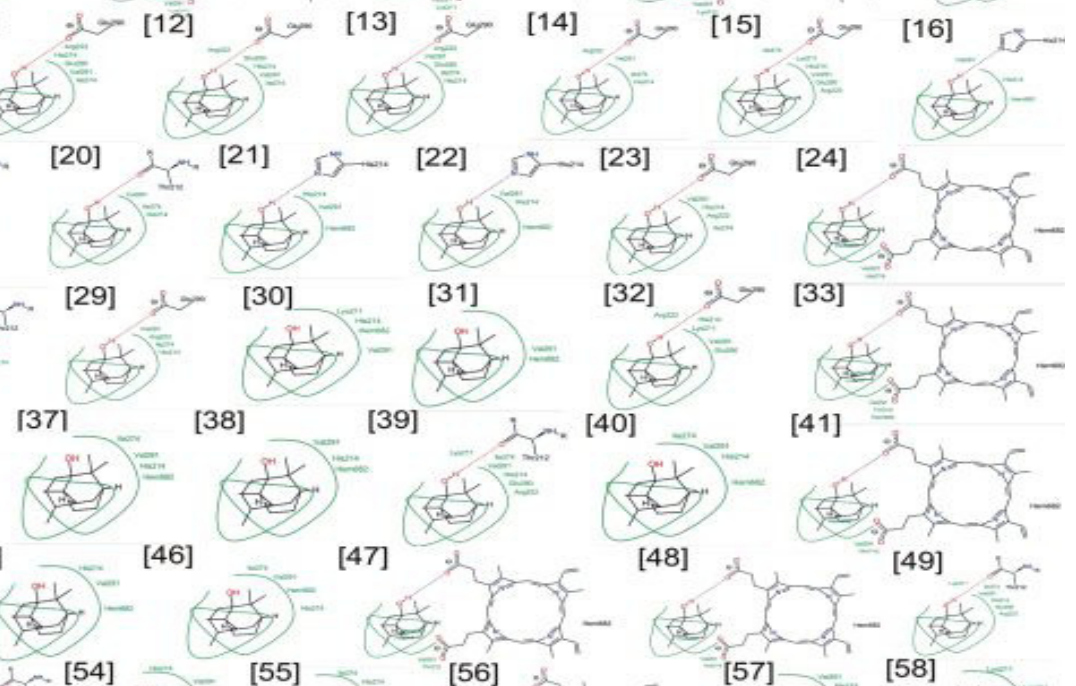

[24]

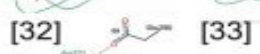

[33]
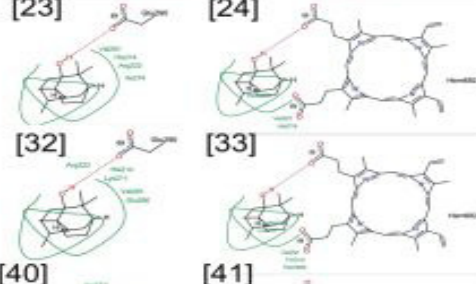
[40]

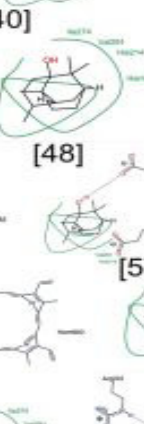

[41]

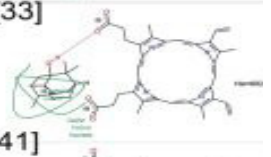
1]
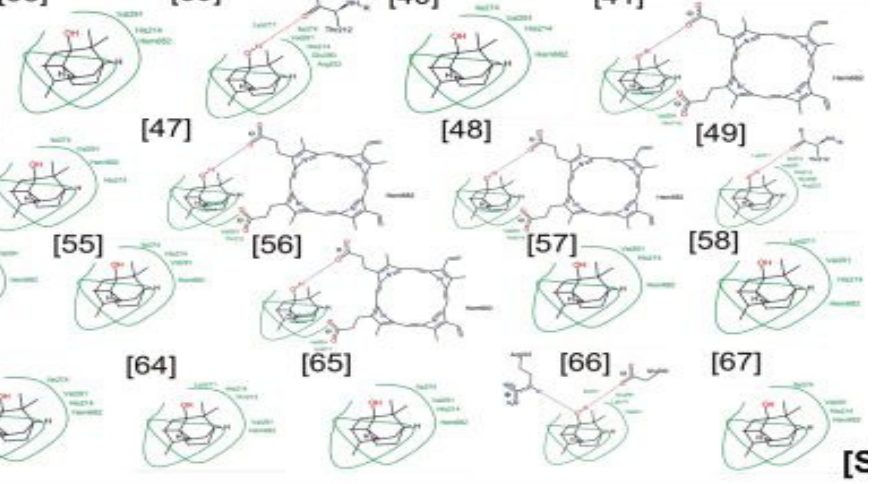

[S

Figure 1. Modeling analyses suggest that alpha-Patchouli alcohol isomers binds to COX-1 and COX-2. [A-C] 3D Structure alpha-patchouli alcohol isomers (CD 521903, CD6432585, and CD442384); [D] COX enzymes in action (Goodsell D.S, 2000) ; [E] Structural representation of COX-1 dimmer [10]; [F] Arachidonic acid bound in the active site of oCOX-1 (Goodsell D.S., 2000) ; [G-I], [J-L]Modeling analysis suggest that alpha-Patchouli alcohol (CD521903/ CD6432585 / CD442384) binds to COX-1 and COX-2, we used by Hex 6.12 Docking Software and Chemira 1.7 Viewer Software. [M-O] [P-R] Modeling analysis suggest that alpha-Patchouli alcohol (CD521903/ CD6432585 / CD442384) binds to COX-1 and COX-2, we used by LigandScout Software. [S] Modelling 2D Hydrogen Bond and energy analyses of alpha-Patchouli alcohol (CD 521903) binding to cyclooxygenase-2, used by LeadIt 2.1.3 Docking and Viewer Software. 
(CD521903, CD442384 and CD6432585) respectively binds with COX-1 and COX-2 in flexible mode, which were include both backbone and side-chains movements. Thereafter, we used LeadIT2 refines the candidate models according to an energy function and hydrogen bond analysis.

\section{Visualization}

All the visualization of the structure files were done using Chemira $1.7 \mathrm{~s}$ molecular graphics system.

\section{RESULT}

The Patchouli plant (Pogostemon cablin Benth) was obtained from the Pujiharjo-Tirtoyudo, Malang and the plants was carried out determination in Plant Anatomy Laboratory, Biology Department, Brawijaya University. Results of determination patchouli plants was Pogostemon cablin Benth, Variety of Sidikalang (Raharjo S.J. \& Retnowati R., 2012). We produced the patchouli oil distillation on $\mathrm{P}_{\text {inlet }} 1,0-1,1$ atm and $\mathrm{P}_{\text {outlet }} 0,9-1,0$ atm. We identified that alpha-patchouli alcohol using Gas Chromatography- Mass Spectrometric (GC-MS) on patchouli oil on $6^{\text {th }}$ fraction as shown Table 1.
We used the Hex 6.12 (rigid docking) to compute possible interaction COX-1 and COX-2 with alpha-Patchouli alcohol isomers (CD521903, CD643285 and CD442384) on its interaction site. The data are represented by chemira $1.7 \mathrm{~s}$ software in Figure 1 (G-I and J-L). Next, van der Waals interactions were calculated by Portable InteLigand-LigandScout 2.02 Software (Figure 1 (M-O and P-R), Furthermore, hydrogen bonding energy was analysed by LeadIT2 software and is shown in Figure 1 (S). The results for all complexes with COX-1 and COX-2 are summarized in Table 2 .

\section{DISCUSSION}

The major compounds of patchouli oil were alpha-patchouli alcohol (MW = 222 g/mol) and alpha-bulnusene, seychellene, alpha-guaiene with MW = $204 \mathrm{~g} / \mathrm{mol}$ were respectively (Raharjo S.J. \& Retnowati R., 2012). The result GC-MS analysis of alpha-patchouli alcohol on patchouli oil on $6^{\text {th }}$ fraction unidentified as single compounds, but these compounds have several isomers. Some of these isomers (CD521903, CD442384 and CD6432585) were using as ligand and these ligands were obtained from pubchem database (http://pubchem.ncbi.nlm. nih.gov/summary) as shown Figure 1 (A-C).

Table 1. Characteristic of Patchouli Oil Component and Fraction of Column Chromatography of Patchouli Oil using analysis of GC-MS Shimadzu QP 2010

\begin{tabular}{|c|c|c|c|c|c|c|c|c|}
\hline \multirow[t]{2}{*}{ No. } & \multirow{2}{*}{$\begin{array}{l}\text { Retention } \\
\text { Time }\end{array}$} & \multicolumn{5}{|c|}{ Patchouli Oil (\% relative) } & \multirow{2}{*}{$\begin{array}{l}\text { Molecular } \\
\text { Weight } \\
(\mathrm{g} / \mathrm{mol})\end{array}$} & \multirow[t]{2}{*}{ Group } \\
\hline & & $\begin{array}{l}\text { Patch } \\
\text { Oil }\end{array}$ & $\begin{array}{l}4^{\text {th }} \\
\text { fraction }\end{array}$ & $\begin{array}{l}6^{\text {th }} \\
\text { fraction }\end{array}$ & $\begin{array}{l}7^{\text {th }} \\
\text { fraction }\end{array}$ & Compounds & & \\
\hline 1. & 12,828 & 5,05 & 6,63 & - & - & alfa-gurjunene & 204 & Sesquiterpenoid \\
\hline 2. & 13,360 & 3,49 & 5,27 & - & - & beta-caryophylene & 204 & Sesquiterpenoid \\
\hline 3. & 13,573 & 19,42 & 25,12 & - & - & alfa-guaiene & 204 & Sesquiterpenoid \\
\hline 4. & 13,798 & 9,25 & 13,20 & - & - & seychellene & 204 & Sesquiterpenoid \\
\hline 5. & 13,977 & 9,15 & 12,68 & - & - & alpha-patchoulene & 204 & Sesquiterpenoid \\
\hline 6. & 14,075 & 1,68 & 1,88 & - & - & gemacrene-D & 204 & Sesquiterpenoid \\
\hline 7. & 14,411 & 3,71 & 5,17 & - & - & gemacrene-A & 204 & Sesquiterpenoid \\
\hline 8. & 14,537 & 21,17 & 28,22 & - & - & alfa-bulnusene & 204 & Sesquiterpenoid \\
\hline 9. & 16,501 & & - & - & 25,84 & viridiflorol & 222 & $\begin{array}{l}\text { Sesquiterpenoid } \\
\text { alcohol }\end{array}$ \\
\hline 10. & 16,755 & 1,17 & 33,60 & 100,0 & 74,16 & patchouli alcohol & 222 & $\begin{array}{l}\text { Sesquiterpenoid } \\
\text { alcohol }\end{array}$ \\
\hline
\end{tabular}

Table 2 Analysis of Virtual Modelling of COX-1/ COX-2-sequiterpenoid/ sesquterpenoid alcohol complexes.

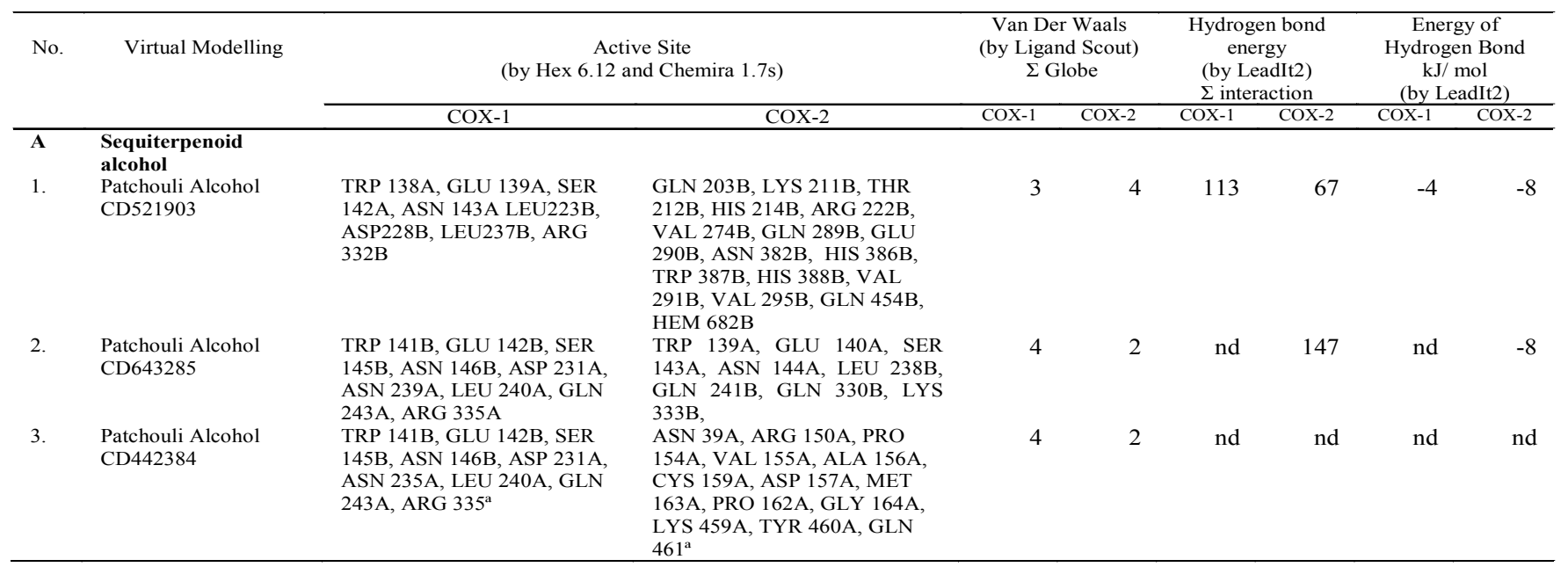


In Figure 1 (D), cyclooxygenase enzyme as showed red color was found in the smooth endoplasmic reticulum and in the nuclear membrane. The enzyme extracts arachidonic acid as showed orange color directly from the membrane and folds it in half, forming a five member ring at the bend and decorating it with peroxides. The resultant molecule was released, and then is modified by the peroxidase active site, which faces into the endoplasmic reticulum. Several additional enzymes then add finishing touches, and the mature prostaglandins (yellow $\mathrm{V}$-shaped molecules) diffuse out of the cell and on to their target (Goodsell, 2000). Structural representation of COX dimmer, as showed in Figure 1 [E]. The N-terminal epidermal growth factor domain is designated in pink and leads into the four R-helices of the membrane binding domain (yellow). Helix D projects up into the COX active site, which is located at the base of the large, globular catalytic domain (cyan). The heme prosthetic group (red) lies in the POX active site (Blobaum \& Marnett, 2007). In Figure $1[\mathrm{~F}]$ as shown arachidonic acid bound in the active site of oCOX-1. The carboxylate of the substrate ion-pairs with Arg-120 and hydrogen-bonds with Tyr-355 at the crowding site, projects up the hydrophobic channel, and makes an L-shaped bend around Tyr-385. The heme prosthetic group is designated in red. Residues that are in contact with arachidonic acid in the active site channel are shown in yellow (Blobaum et al., 2007). COX-1 and COX-2 are two distinct isoforms of cyclooxgenase, and plays a vital role in conversion of arachidonic acid to prostaglandin. Prostaglandins are involved in various pathological processes like inflammatory responses, carcinogenesis and cardiovascular events (Amaravani, Prasad, \& Ramakrishna, 2012). These theoretical data suggests alphapatchouli alcohol (CD521903, CD442384, CD6432585) as potential inhibitor of COX-1 (Raharjo S.J. \& Fatchiyah, 2013). These virtual predictive can be used preliminary selective or non selective COX-1 and COX-2.

Rigid docking to compute possible interaction COX-1 and COX-2 with alpha-Patchouli alcohol isomers (CD521903, CD643285 and CD442384) on its interaction site and the interaction result, as shown on Figure 1 (G-I and J-L), van der Waals interaction, as shown on Figure 1 (M-O and P-R) and hydrogen bonding energy, as shown in Figure 1 (S). The results for all complexes with COX-1 and COX-2 are summarized in Table 2.

In silico analysis was predicting patchouli oil compounds as candidate ligand receptor to using cyclooxgenase-1 (COX-1 or PGH1 mouse) and cyclooxgenase-2 (COX-2 or PGH2 mouse). All isomers have ability as inhibitor COX-1 and COX-2, but the best modeling analyses suggest that alpha-patchouli alcohol isomer compounds of patchouli oil was alpha-patchouli alcohol (CD521903-COX-1 complexes and CD521903 COX2 complexes). Modeling analysis suggest that alpha-Patchouli alcohol (CD521903) binds to COX-1 at active sites including: LEU223B, ASP228B, LEU237B, ARG 332B, TRP 138A, GLU 139A, SER 142A, ASN 143A, and the interaction to COX2 at active site including: GLN 289B, GLU 290B, ARG 222B, LYS 211B, THR 212B, HIS 214B, ASN 382B, HEM682B, GLN 454B, HIS 386B, TRP 387B, HIS 388B, VAL 274B, GLN 203B, VAL 291B, VAL 295B, as shown Figure 1 [S]. We conducted interaction hydrogen bond energy (with none model solvent) between alpha-patchouli alcohol: CD521903-COX-1 complexes $(-4 \mathrm{~kJ} / \mathrm{mol})$ and CD521903-COX-2 complexes $(-8 \mathrm{~kJ} /$ $\mathrm{mol})$. In silico analysis will suggest the ability patchouli alcohol CD521903 as inhibitor cyclooxgenase-2 selective novelty.
Modeling analysis suggest that alpha-Patchouli alcohol (CD521903) binds to COX-2 at active site including: GLN 289B, GLU 290B, ARG 222B, LYS 211B, THR 212B, HIS 214B, ASN 382B, HEM682B, GLN 454B, HIS 386B, TRP 387B, HIS 388B, VAL 274B, GLN 203B, VAL 291B, VAL 295B, so that complex formation CD521903-COX-2 would blocking oxygenated reaction and peroxides reaction currently arachidonic acid substrate into the enzyme COX-2. When compared of establishment with the COX-1-CD521903 complexes, CD521903-COX-2 complexes over selective as COX-2 inhibitors. Also supported, hydrogen bond energy (None Model Solvent) $\mathrm{CD}-521903-\mathrm{COX}-1$ complexes $(-4 \mathrm{~kJ} / \mathrm{mol})$ was smaller than the CD-521093-COX-2 complexes $(-8 \mathrm{~kJ} / \mathrm{mol})$ by LeadIt 2 software. Collectively, our results suggest that alpha-Patchouli alcohol (CD-521903) is suggesting an inhibitor of COX-2 selective by LeadIt2 software. Further in silico analysis using molecular dynamic virtual by Amber12 software. And also in silico data await conformation by biological activity analysis.

\section{ACKNOWLEDGEMENTS}

This study supported by Doctoral program scholarship of "BPPDN-DGHE", Ministry of Education and Culture, RI. We thank you for all facilities of biological computer Laboratory Department of Biology, Brawijaya University providing the in silico analyses. Thanks to Nashi Widodo and Didik H. Utomo (Biology Department, Brawijaya University) acknowledged for helpful discussions.

\section{REFERENCE}

Amaravani, M., Prasad, N. K., \& Ramakrishna, V. (2012). COX-2 structural analysis and docking studies with gallic acid structural analogues. SpringerPlus, 1(1): 1-7.

Blobaum, A. L., Marnett, L. J., \& Introduction, I. (2007). Structural and Functional Basis of Cyclooxygenase Inhibition. Journal of Medical Chemistry, 50(7): 1425-41.

Dannhardt, G., \& Laufer, S. (2000). Structural Approaches to Explain the Selectivity of COX-2 Inhibitors: Is There a Common Pharmacophore? Current Medicinal Chemistry, 7(11), 1101-12.

Goodsell, D. S. (2000). The Molecular Perspective: Cyclooxygenase-2. The Oncologist, 5(2), 169-171.

Kartasasmita, R. E. (2002). The Develompment NSAID. Acta Pharmaceutica Indonesia, XXVII(4), 75-91.

Raharjo, S J, Retnowati, R., \& Soebiantoro. (2012). Karakteristik minyak nilam hasil optimasi waktu distilasi uap daun nilam. Natural, I(4), 1-8.

Raharjo, S.J., \& Fatchiyah, F. (2013). Virtual screening of compounds from the patchouli oil of Pogostemon herba for COX-1 inhibition. Bioinformation, 9(6), 322-324.

Raharjo, S.J., \& Retnowati, R. (2012). Yield Increasing Of Patchouli Oils Of Result Steam Distillation Of Patchouli Leaf Of Dewaxing, Fermentation, And Drying Process. Journal Basic Science And Technology, 1(3), 12-18.

Raharjo, S. J., \& Yusuf, A. R. (2012). Increasing of alpha-patchouli alcohol with pressure variations in steam distillation of patchouli plants (Pogostemon cablin Benth). Sain Med (Jurnal Kesehatan), 4(2), 124-30.

Tsai, Y.C., Hsu, H.C., Yang, W.C., Tsai, W.J., Chen, C.C., \& Watanabe, T. (2007). Alpha-bulnesene, a PAF inhibitor isolated from the essential oil of Pogostemon cablin. Fitoterapia, 78(1), 7-11.

Wang, D., Yin, Z., Zhang, Q., Ye, W., Zhang, X., \& Zhang, J. (2010). [Nonvolatile chemical constituents from Pogostemon cablin]. China journal of Chinese materia medica, 35(20), 2704-7.

Xian, Y.F., Li, Y.C., Ip, S.-P., Lin, Z.X., Lai, X.P., \& Su, Z.R. (2011). Anti-inflammatory effect of patchouli alcohol isolated from Pogostemonis Herba in LPS-stimulated RAW264.7 macrophages. Experimental and Therapeutic Medicine, 2(3), 545-550.

Zukhrullah, M., \& Aswad, M. (2012). Kajian beberapa senyawa antiinflamasi : Docking terhadap sikoloksigenase-2 secara ini silico. Majalah Farmasi dan Farmakologi, 16(1), 37-44. 